\title{
Diclofenac Potassium Transdermal Patches Using Natural Rubber Latex Biomembranes as Carrier
}

\author{
Natan Roberto de Barros, ${ }^{1}$ Paulo Augusto Marques Chagas, ${ }^{2}$ \\ Felipe Azevedo Borges, ${ }^{1}$ Jose Lucio Padua Gemeinder, ${ }^{2}$ Matheus Carlos Romeiro Miranda, ${ }^{1}$ \\ Bruna Cambraia Garms, ${ }^{1}$ and Rondinelli Donizetti Herculano ${ }^{3}$ \\ ${ }^{1}$ Chemistry Institute, São Paulo State University, 55 Prof. Francisco Degni Street, 14800-060 Araraquara, SP, Brazil \\ ${ }^{2}$ Faculty of Language \& Sciences, São Paulo State University, 2100 Dom Antonio Avenue, 19806-900 Assis, SP, Brazil \\ ${ }^{3}$ Pharmaceutical Sciences Faculty, São Paulo State University, Km 01, Araraquara-Jau Road, 14801-902 Araraquara, SP, Brazil
}

Correspondence should be addressed to Natan Roberto de Barros; natan501@hotmail.com

Received 29 June 2015; Accepted 25 October 2015

Academic Editor: Eugen Culea

Copyright (C) 2015 Natan Roberto de Barros et al. This is an open access article distributed under the Creative Commons Attribution License, which permits unrestricted use, distribution, and reproduction in any medium, provided the original work is properly cited.

\begin{abstract}
The aim of this study was to design a compound transdermal patch containing diclofenac potassium (Dic-K) using natural rubber latex (NRL) biomembrane. The NRL from Hevea brasiliensis is easily manipulated and low cost and presents high mechanical resistance. It is a biocompatible material which can stimulate natural angiogenesis and is capable of adhering cells on its surface. Recent researches have used the NRL for Transdermal Drug Delivery Systems (TDDSs). Dic-K is used for the treatment of rheumatoid arthritis and osteoarthritis and pain relief for postoperative and posttraumatic cases, as well as inflammation and edema. Results showed that the biomembrane can release Dic-K for up to 216 hours. The kinetics of the Dic-K release could be fitted with double exponential function. X-ray diffraction and Fourier Transform Infrared (FTIR) spectroscopy show some interaction by hydrogen bound. The results indicated the potential of the compound patch.
\end{abstract}

\section{Introduction}

Diclofenac (Dic) is a well-known nonsteroidal antiinflammatory drug (NSAID) with anti-inflammatory, analgesic, and antipyretic properties, comparable or superior to other NSAIDs [1]. Dic shows preferential inhibition of the cyclooxygenase-2 (COX-2) enzyme [2]. Diclofenac sodium (Dic-Na) is mainly indicated in the treatment of osteoarthritis, rheumatoid arthritis, and ankylosing spondylitis. Dic-K is claimed to dissolve faster and hence absorbed faster than the sodium salt and is recommended for the treatments that need short onset of action, mainly for its analgesic properties. Dic-K is also indicated for the treatment of primary dysmenorrheal and mild to moderate pain [3]. As with other NSAIDs, Dic is known to increase higher risk of gastrointestinal bleeding and cardiovascular side effects [3]. However, Dic has a relatively high therapeutic index in comparison to other NSAIDs [4].

The majority of pharmacokinetic data concerns Dic-Na. Literature reports indicate that Dic-Na and Dic-K are similar in terms of extent of oral absorption, patterns of distribution, metabolism, and elimination [5].

Dic is $100 \%$ absorbed after oral administration, compared to intravenous administration, based on urine recovery studies [6]. Dic shows linear pharmacokinetics. Absorption of Dic occurs throughout the intestinal tract; its rapid and complete absorption suggests a high permeability through the intestinal membrane [7]; however only about $60 \%$ of drug reaches the systemic circulation due to first pass metabolism [8]. This observation of high permeability throughout the intestinal tract is also supported by reports of rapid absorption of Dic from effervescent tablets and the high permeability of Dic in the colon after administration of the drug as a suppository $[9,10]$.

The apparent volume of distribution is $1.3 \mathrm{~L} \cdot \mathrm{kg}^{-1}$ for Dic-K and $1.4 \mathrm{~L} \cdot \mathrm{kg}^{-1}$ for Dic-Na [3, 11]. Circulating Dic is known to be greater than $99 \%$ bound to human serum protein, primarily to albumin [12]. However, this binding has been described as pharmacokinetically insignificant due to 


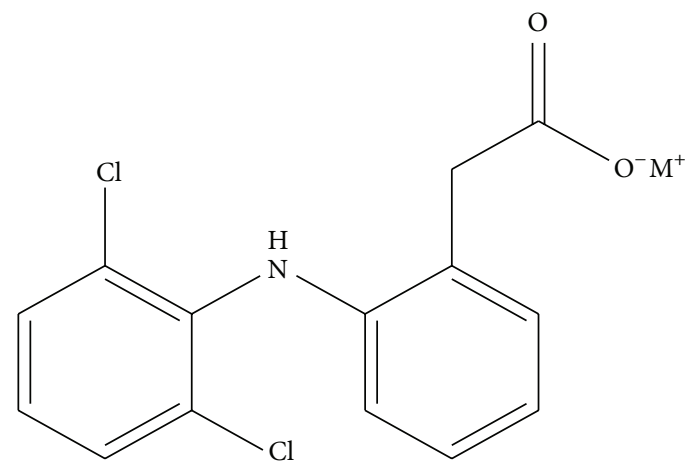

FIgURE 1: Structure of Dic, with $\mathrm{M}=\mathrm{K}^{+}$or $\mathrm{Na}^{+}$for potassium or sodium salt, respectively.

the rapid association-dissociation of Dic to albumin, such that the drug readily dissociates and permeates across the vascular membrane to the tissues [5]. The chemical name of Dic is 2-[(2,6-dichlorophenyl)amino]-benzeneacetic acid. Its structure is shown in Figure 1.

People who use nonsteroidal anti-inflammatory drugs (NSAIDs) (other than aspirin) may have a higher risk of having a heart attack or a stroke than people who do not use these medications. These events may happen without warning and may cause death. The risk may be higher for people who use NSAIDs for a long time [13].

Transdermal Drug Delivery offers many advantages such as reduced side effects, less frequent administration to produce the desired constant plasma concentration associated with improved patient compliance, elimination of the firstpass effect, sustained drug delivery, and interruption of treatment when necessary. NSAIDs are mostly used for the preparation of transdermal patches for treatment of pain or inflammation [14].

So, the aim of this study was to design a compound transdermal patch (biomembrane) containing Dic-K as an alternative way of drug delivery which can maintain a uniform plasma concentration and avoid the gastrointestinal action [15].

Polymers have played a key role in advancing drug delivery technology, providing the controlled release of therapeutic agents at constant rates over long periods, cyclic and adjustable release dosage of hydrophilic as well as hydrophobic drugs. The demand for biomaterials with features that provide controlled release of drugs is constant and necessary; a candidate for this application is a biopolymer, the NRL.

Poly(cis-1,4-isoprene), the major polymer from NRL obtained from Hevea brasiliensis, has interesting properties such as biocompatibility, high mechanical resistance, and capability to form a film. Mrue et al. (2014) were the first to use NRL membranes as a prosthesis of a cervical esophagus segment in dogs [16]. Sader et al. (2000) studied the behavior of NRL membrane as a partial substitute of dogs pericardium [17]. Herculano et al. (2009) have demonstrated the use of natural latex extracted from the rubber tree Hevea brasiliensis as a template for controlled release systems, showing promising results for future biomedical applications [18].
The rubber particles in the latex represent $30-45 \%$ of the total volume and $90 \%$ by dry weight of latex. These particles are generally spherical and ovoid but may be pearshaped and vary considerably in size between $60 \AA$ and 5$6 \mu \mathrm{m}$ [19]. They consist mainly of poly(cis-1,4-isoprene), a polymer of high molecular weight: $500-2000 \mathrm{kDa}$ [20]; the particles are coated with a thin layer of phospholipids and proteins. Negative charges present in this layer ensure the stability of the colloidal middle [21]. Lipids and phospholipids which form this layer consist in 1.4 to $3.2 \%$ by weight of rubber and contain 0.4 to $1.2 \%$ of neutral lipids [22].

Recently, the use of a polymer from NRL for TDDSs has been reported $[23,24]$. NRL biomembrane is an important inductor of the healing process of wounds, being used in several medical applications like prosthetics and bone grafts [25]. Moreover, the treatment of diabetic and phlebopathic ulcers with this membrane leads to a faster healing process due to a vascular growth factor found in the latex and due to a physical blockage of the entrance of new infectious agents in the treated site [26]. To summarize, the NRL biomembrane has some interesting characteristics such as easy manipulation, low cost, the ability to stimulate natural angiogenesis and cellular adhesion, being a biocompatible material, and the ability to present high mechanical resistance [25].

In this study, novel Dic-K transdermal patches using NRL biomembrane are proposed for a sustained release of the drug, for further optimization of the local anti-inflammation action, avoiding some complications and possibly being a future application in medicine as surgical bandage for bone and tissue regeneration. Results showed that the NRL biomembrane can release Dic-K for up to $216 \mathrm{~h}$, which is relevant for biomedical applications. In addition, the X-ray diffraction (XRD), Scanning Electron Microscopy (SEM), and Fourier Transform Infrared (FTIR) are also reported and showed that it is relevant for biomedical applications.

\section{Experimental}

In the present study the NRL used was commercial highammonia from BDF Rubber Latex Co. Ltd. (producer and distributor of concentrated rubber latex, Guarantã, Brazil) of about $60 \%$ dry rubber content, $4-5 \%$ weight of nonrubber constituents such as protein, lipids, carbohydrates, and sugar, and $35 \%$ of water [27]. After extraction, ammonia was used to keep the latex liquid. NRL was centrifuged at $8,000 \mathrm{~g}$ to reduce particularly the allergenic content. The cream fraction after centrifugation was redispersed to make the desired $60 \%$ of dry rubber content latex and then washed twice by centrifugation to reduce the cytotoxic protein content on the solution.

Dic-K $\left(\mathrm{C}_{14} \mathrm{H}_{10} \mathrm{Cl}_{2} \mathrm{KNO}_{2}\right)$ was obtained in gel capsules, without excipients. Each of them contained $100 \mathrm{mg}$ of ciprofloxacin in powder form. The capsules were purchased from Callithea Pharmaceutics Ltd., Brazil.

The NRL biomembranes loaded with Dic-K were prepared by mixing $3 \mathrm{~mL}$ of $\mathrm{NRL}$ and $3 \mathrm{~mL}$ of Dic-K solution $\left(3 \mathrm{mg} \mathrm{mL}^{-1}\right)$; then, the mixture was poured onto glass plates 


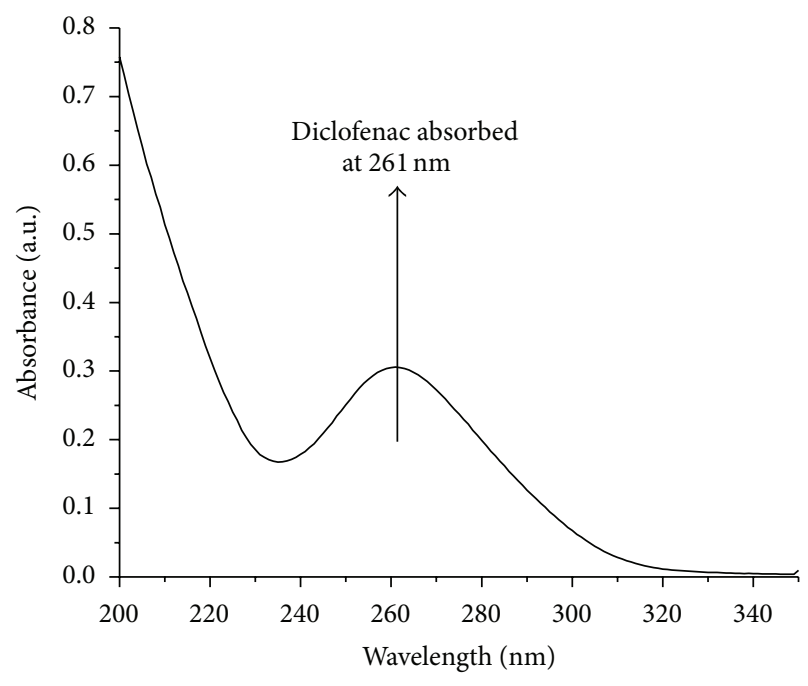

(a)

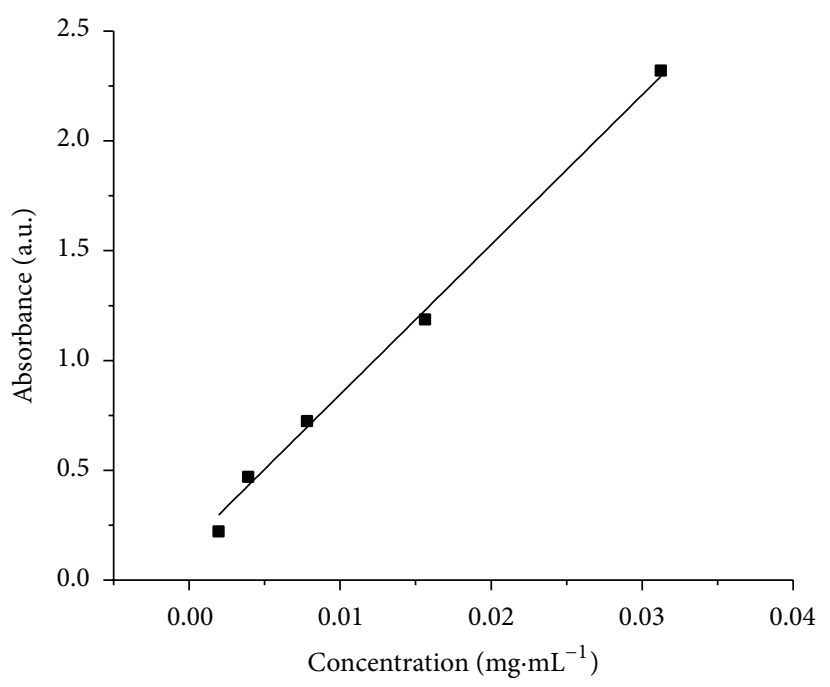

(b)

FIgURE 2: (a) UV spectrum of Dic-K in solution. (b) Absorbance intensity as a function of Dic-K concentration in solution.

with $5.00 \pm 0.05 \mathrm{~cm}$ diameter and $243.40 \pm 0.05 \mu \mathrm{m}$ thickness. Membranes were maintained at room temperature $\left(25^{\circ} \mathrm{C}\right)$ for two days until complete polymerization. For the release study, NRL biomembranes with Dic-K were placed in $300 \mathrm{~mL}$ of an aqueous solution in triplicate, from which aliquots were collected during an interval ranging from 0 to 250 hours. The Dic-K released into the solution was monitored by measuring the UV-vis spectra with a Bel Engineering SF200 ADV spectrophotometer, as Dic-K has a maximum absorption at $261 \mathrm{~nm}$.

Figure 2 shows the absorbance intensity as a function of Dic-K concentration in solution. This calibration curve is important to make one relationship between absorbance and the Dic-K concentration. For this experiment several Dic-K concentrations from $1.2 \times 10^{-3}$ to $3.1 \times 10^{-2} \mathrm{mg} \mathrm{mL}^{-1}$ were made. After this, the absorbance was measured. Each drug concentration (point) was made in triplicate, where the estimated error was minor as $5 \%$. The calibration curve shows straight line and obeys Lambert-Beers Law. The regression coefficient is 0.9761 , intercept is $0.1636 \pm 0.0857$, and slope is $68.1853 \pm 5.3116$.

The biomembranes were characterized by X-ray powder diffraction (XRD), using a Siemens D5005 X-ray diffractometer and a graphite crystal as monochromator to select $\mathrm{Cu}$ $\mathrm{K} \alpha 1$ radiation $(1.5406 \AA)$, in a step of $0.02^{\circ} \mathrm{s}^{-1}$. The surface morphology of the NRL membrane was observed using a Scanning Electron Microscopy (SEM) model Zeiss EVO 50 $(20 \mathrm{KV})$ and a take-off angle of $35^{\circ}$.

The FTIR spectra of the pure Dic-K, pure NRL, and NRL + Dic-K were obtained to prove the chemical integrity of the drug in the polymer. The samples were measured directly by Attenuated Total Reflection (FTIR-ATR) method, which is an excellent method for obtaining infrared information for the powder sample surface. The biomembranes were characterized using a TENSOR 27 (Bruker, Germany) (4000$500 \mathrm{~cm}^{-1}$ ) with a resolution of $4 \mathrm{~cm}^{-1}$ with 64 scans.

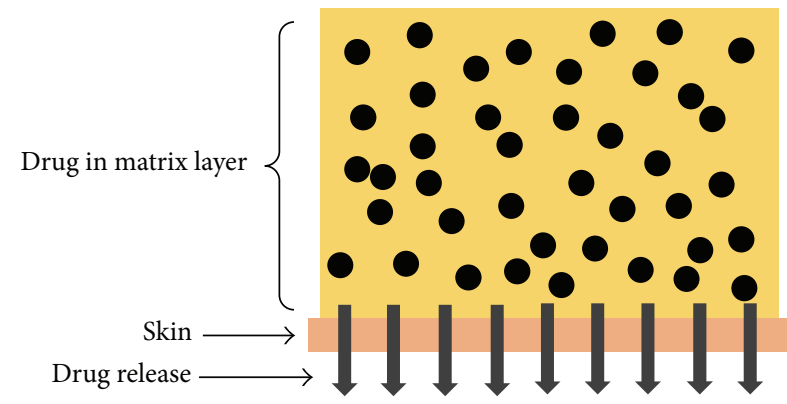

FIGURE 3: Schematic illustrations of Dic-K transdermal patches using natural rubber latex biomembrane.

\section{Results and Discussion}

Controlled release drug delivery systems are being developed to address many of the difficulties associated with traditional methods of administration. This system employs devices-such as polymer-based disks, rods, pellets, or microparticles-that encapsulate drug and release it at controlled rates for relatively long periods of time. Such systems offer several potential advantages over traditional methods of administration. First, drug release rates can be tailored to the needs of a specific application, for example, providing a constant rate of delivery or pulsatile release. Second, controlled release systems provide protection of drugs, especially proteins, which are otherwise rapidly destroyed by the body. Finally, controlled release systems can increase patient comfort and compliance by replacing frequent (e.g., daily) doses with infrequent (once per month or less) injection [28].

The aim of this study was to prepare the Dic-K transdermal delivery systems patch using NRL biomembrane. The structure of drug transdermal patches using NRL biomembrane is showed as in Figure 3. 


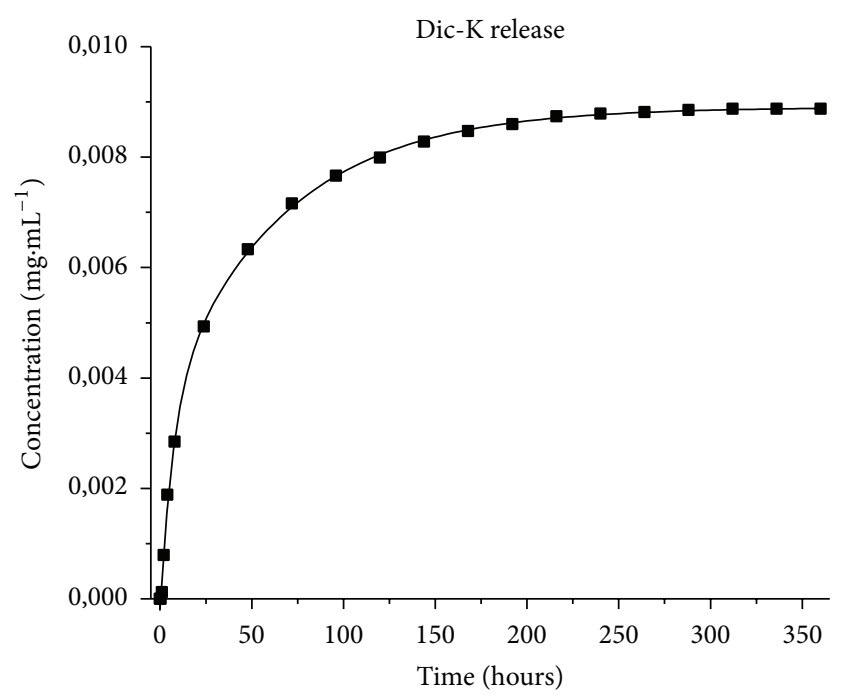

FIGURE 4: Dic-K release as a function of time for NRL biomembrane prepared at room temperature. Notice that the Dic-K concentration reaches a plateau after approximately $216 \mathrm{~h}$.

As can be seen in Figure 4, the intensity of the absorbance due to the increase of drug concentration increases with time. A large drug release in solution during the first hours of the experiment can be noticed due to the portion of the drug present on the surface of the membranes. This is followed by a slower release which occurs due to the membrane water permeability. The functionalized membranes with Dic-K were able to release $20 \%$ of the drug in solution over a period of 216 hours ( 9 days); the failure to release larger amount of the drug could be associated, possibly, with the pore density on the membrane surface. When NRL membranes are made at room temperature $\left(25^{\circ} \mathrm{C}\right)$, the surface pore density is lower as compared to NRL membranes made at lower temperatures [29].

Another factor that may have influenced the amount of drug released is the possibility of forming "pockets," small spaces formed by drug crystals wrapped in NRL, with absence of pores, which may preclude a more efficient release. One strategy that can be used to increase the percentage of drug released is the production of membranes with greater pore density.

The experimental release studies were fitted using a biexponential function, $y(t)=y_{0}+A_{1} e^{-t / \tau 1}+A_{2} e^{-t / \tau 2}$, where $y(t)$ is the amount of Dic-K in the NRL at a given time, $t, y_{0}$ is the initial content of the drug, and $A_{1}$ and $A_{2}$ are constants, equal to $-0.0036 \pm 2.7484 \times 10^{-4}$ and $-0.0055 \pm 2.6168 \times$ $10^{-4}$, respectively, and the characteristic times $\left(\tau_{1}\right.$ and $\left.\tau_{2}\right)$ are $7.0669 \pm 0.8305$ hours and $64.6054 \pm 4.2500$ hours. The slower release process is associated with the Dic-K diffusing slowly through the matrix. Thus, the drug is also found in the inner portion of the polymeric matrix. The Dic-K release depends mainly on the amount of encapsulated material (as a reservoir).

Figure 5 shows the FTIR spectra for pure Dic-K, pure NRL, and NRL + Dic-K. The FTIR of Dic-K showed that the

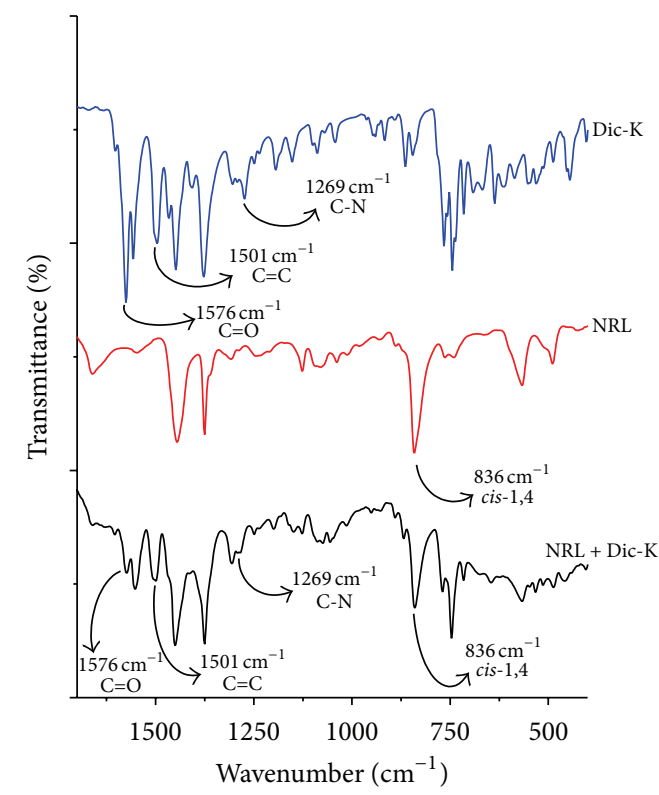

FIGURE 5: FTIR-ATR spectra of K-Dic, NRL, and NRL loaded with drug.

principal IR bands at $1269 \mathrm{~cm}^{-1}$ resulted from C-N stretching, and bands at $1501 \mathrm{~cm}^{-1}$ and $1576 \mathrm{~cm}^{-1}$ resulted from $\mathrm{C}=\mathrm{C}$ stretching and $\mathrm{C}=\mathrm{O}$ stretching of carboxylate group, respectively. The FTIR of NRL showed that the principal IR band at $836 \mathrm{~cm}^{-1}$ corresponding to $=\mathrm{CH}$ out of plane bending resulted from cis-1,4 stretching, frequently used for identifying this molecule. Besides this, other characteristics absorption bands were also observed for the NRL, and the absorption band observed at $572 \mathrm{~cm}^{-1}$ corresponds to the CC deformation of NRL backbone, $1240 \mathrm{~cm}^{-1}$ corresponding to O-P-O asymmetric stretching of phospholipids. The $\mathrm{CH}_{2}$ symmetric stretching vibrations are observed at the region $2852-2925 \mathrm{~cm}^{-1}$. The $\mathrm{CH}_{3}$ asymmetric stretching is observed at $2961 \mathrm{~cm}^{-1}$. These FTIR correlations for NRL are consistent with the earlier work [30]. Additionally, the FTIR spectrum of NRL + Dic-K showed the characteristic bands observed to Dic-K as by NRL, proving the stability of the drug after its incorporation into the biomembrane.

The XRD pattern for NRL membranes, powder Dic-K, and NRL membranes prepared with $3 \mathrm{~mL}$ solution $3 \mathrm{mg} \mathrm{mL}^{-1}$ of Dic- $\mathrm{K}$ is shown in Figure 6, where we can see the amorphous nature of NRL biomembranes, as expected, with a broad peak at $19^{\circ}$ in $2 \theta$. In contrast, powder Dic-K exhibits an XRD pattern of a crystalline material with no amorphous component with sharp peaks appearing in 7, 8, 9, 11, 15, 22.5, and $27.20^{\circ}$ according to Semalty et al. (2009) [31]. But when drug was incorporated into the polymer the intensities of peaks were decreased due to decreased crystallinity of the Dic-K [32]. The absence of crystallinity in the NRL membrane with Dic-K indicates that the Dic-K is molecularly dispersed or captive in the NRL microparticles.

Although NRL biomembranes with Dic-K show a broader spectrum DRX than the accented spectrum of pure NRL biomembranes, the FTIR spectrum shows that there is 


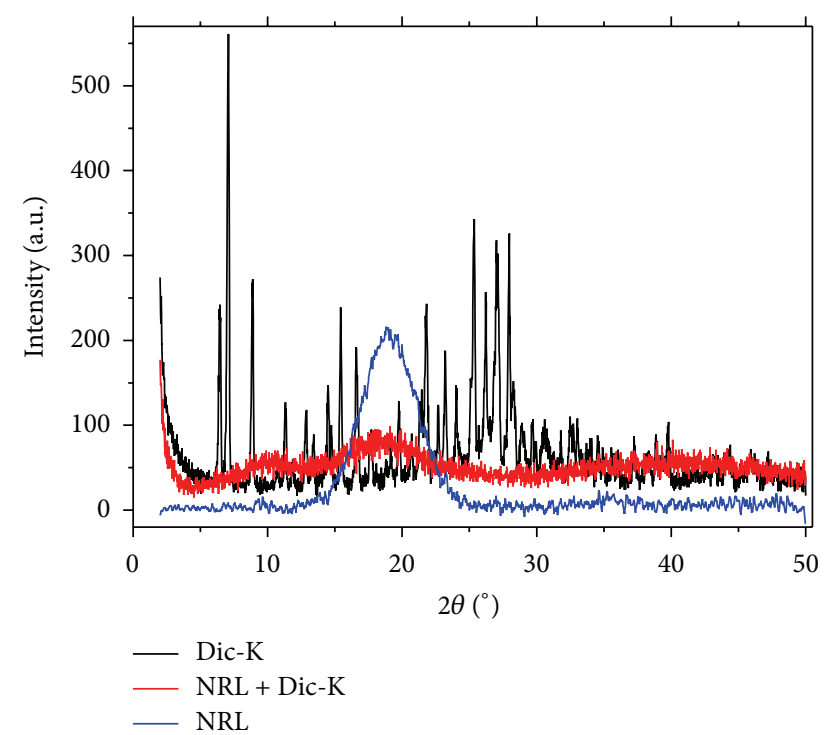

Figure 6: X-ray diffraction pattern of natural latex (blue line), Dic-K powder (black line), and NRL membrane prepared with $3 \mathrm{mg} \cdot \mathrm{mL}^{-1}$ of Dic-K (red line).

no chemical interaction between the NRL and Dic-K, since no new absorption peaks appeared.

Figure 7 shows the pure Dic-K and NRL membrane functionalized with Dic-K; note that a reasonable amount of drug is found on the membrane surface; this drug moiety on the surface is responsible for the fast release during the first hours.

In this study, the method proposed by Langer and Folkman was used [33], that is, to mix the drug with the polymer (latex) in a colloidal state, in order to create a biomembrane that works as a delivery system, without use of additives or organic solvents.

Various approaches have been used for delivery of drugs which include coating with design of time release dosage forms and the utilization of carriers (as chitosan, pectin, inulin, alginate, and guar gum).

Suksaeree et al. (2012) [24] developed one novel nicotine transdermal patch (NTP) using deproteinized natural rubber latex (DNRL) blended with hydroxypropylmethyl cellulose (HPMC) and dibutylphthalate (DBP).

Already Löbler et al. (2011) [34] developed a device based on polyhydroxyalkanoates (PHA) for implantation of a glaucoma drainage system. In this study, PHA based on hydroxybutyric acid was tested in terms of its potential suitability to manufacture mechanically stable tube components of drug delivery drainage systems and in terms of biocompatibility.

Goddard et al. (1990) [35] showed that the presence of an adsorbed layer of surface-active phospholipids on the surface of the mucus that covers the surface epithelium is suggested to protect the GI tissues by providing a hydrophobic layer between the epithelium and the luminal contents.
Herculano et al. (2010) [29] proposed a drug release system based on NRL for the sustained and controlled delivery of nitric oxide (NO). They concluded that the release time of nitric oxide in in vitro assays was very promising for the kinetics of release. In addition, Murbach et al. (2014) [25] proposed Transdermal Drug Delivery Systems (TDDSs) based on latex for the sustained and controlled delivery of ciprofloxacin (CIP), although the NRL were able to release $59 \%$ of ciprofloxacin.

Moreover, Maswadeh et al. (2004) [36] improved the efficiency of encapsulation of Dic-Na into uncoated and chitosan-coated liposomes. The encapsulation varied from 59 to $99 \%$. By the methodology employed in this work, all drugs were retained in the membrane.

Wang et al. (2006) [37] prepared uniform-sized chitosan microspheres by membrane emulsification technique. Uniform chitosan microspheres were further used as a carrier of a protein drug bovine serum albumin (BSA). They observed that BSA loading efficiency was highest when $\mathrm{pH}$ value was 8.09 , and it decreased with an increase of the cross-linking degree. The controlled release of drug/proteins/molecules/extracts is of interest for medical applications, since the dose can be adjusted according to the application envisaged.

Tariq et al. (2012) [38] observed that with lower polymer/ Dic-K ratio the rate and extent of drug release were higher than from higher polymer/Dic-K ratio, due to its decreased porosity. Also, the release was retarded from carnauba wax matrix due its hydrophobicity. Ray et al. (2011) [39] also observed that the alginate/polymer ratio controls the release rate of the drug. The Dic-K release is decreased when the HPMC polymer concentration is increased.

\section{Conclusions}

We have prepared NRL biomembranes containing Dic-K as a model system for transdermal patches. The method of preparation is reproducible and the latex biomembrane is very stable. The XRD shows that the absence of crystallinity in the Dic-K/NRL biomembrane indicates that Dic-K is molecularly dispersed within the microparticles. FTIR indicated that Dic-K did not interact chemically with the biomembrane. Nevertheless, the NRL biomembrane was able to release $20 \%$ of the Dic-K in 9 days and could be fitted by a biexponential equation which can help to predict the release of the drug. The SEM photographs indicated that drug was present both inside and on the surface of the polymeric matrix, thus making it a promising material for drug release in in vivo applications. This study presented a novel transdermal patch specific drug delivery system containing Dic-K.

\section{Conflict of Interests}

The authors declare that there is no conflict of interests regarding the publication of this paper. 


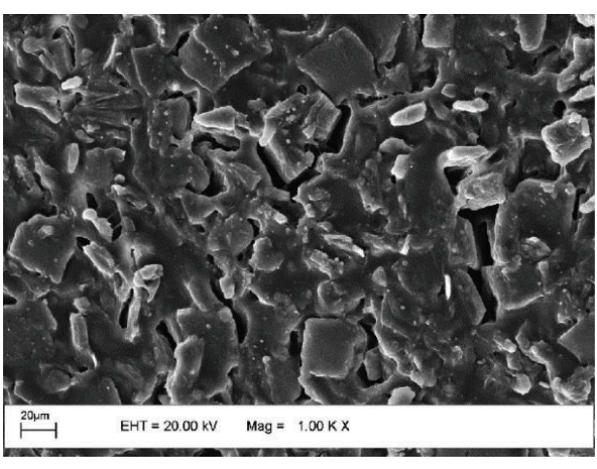

(a)

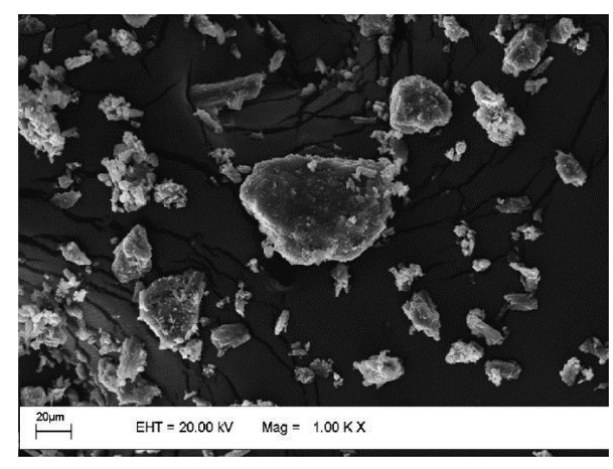

(b)

FIGURE 7: SEM micrography of (a) potassium diclofenac powder and (b) NRL membrane + potassium diclofenac. Note that the Dic-K is present in the NRL matrix.

\section{Acknowledgments}

This work was supported by PROPe/UNESP, CNPq/PIBIC, FUNDUNESP (Process: 193/2011), and FAPESP (Process: 2011/17411-8).

\section{References}

[1] W. Riess, H. Stierlin, P. Degen et al., "Pharmacokinetics and metabolism of the anti-inflammatory agent voltaren," Scandinavian Journal of Rheumatology, vol. 7, no. 22, pp. 17-29, 1978.

[2] B. Hinz, T. Rau, D. Auge et al., "Aceclofenac spares cyclooxygenase 1 as a result of limited but sustained biotransformation to diclofenac," Clinical Pharmacology and Therapeutics, vol. 74, no. 3, pp. 222-235, 2003.

[3] Cataflam, Novartis Pharmaceuticals Corporation, May 2015, https://www.pharma.us.novartis.com/product/pi/pdf/Cataflam .pdf.

[4] P. Brundig, R.-H. Borner, R. Haerting, V. Janitzky, and A. Schlichter, "Glycose aminoglycane excretion and concentration in the urine of patients with frequently recurrent calciumoxalate lithiasis prior to and following Diclofenac-Na therapy," Urological Research, vol. 18, no. 1, pp. 21-24, 1990.

[5] N. Moore, "Diclofenac potassium 12.5mg tablets for mild to moderate pain and fever: a review of its pharmacology, clinical efficacy and safety," Clinical Drug Investigation, vol. 27, no. 3, pp. 163-195, 2007.

[6] S. Kiran, M. Rajendra, P. Yogesh, and S. Aamir, "Fundamentals of drug delivery system," in Drug Delivery Systems: A Review, A. V. Gothoskar, Ed., vol. 1, chapter 1, pp. 10-17, 2012.

[7] M. J. Kendall, D. P. Thornhill, and J. V. Willis, "Factors affecting the pharmacokinetics of diclofenac sodium (Voltarol)," Rheumatology and Rehabilitation, vol. 2, supplement 2, pp. 3846, 1979.

[8] B. Hinz, J. Chevts, B. Renner et al., "Bioavailability of diclofenac potassium at low doses," British Journal of Clinical Pharmacology, vol. 59, no. 1, pp. 80-84, 2005.

[9] B. Terhaag, A. Hoffmann, M. Barkworth, and B. Vens-Cappell, "Bioavailability of a new effervescent tablet of diclofenac," International Journal of Clinical Pharmacology and Therapeutics, vol. 38, no. 11, pp. 546-551, 2000.

[10] N. M. Idkaidek, G. L. Amidon, D. E. Smith, N. M. Najib, and M. M. Hassan, "Determination of the population pharmacokinetic parameters of sustained-release and enteric-coated oral formulations, and the suppository formulation of diclofenac sodium by simultaneous data fitting using NONMEM," Biopharmaceutics and Drug Disposition, vol. 19, no. 3, pp. 169-174, 1998.

[11] B. Chuasuwan, V. Binjesoh, J. E. Polli et al., "Biowaiver monographs for immediate release solid oral dosage forms: diclofenac sodium and diclofenac potassium," Journal of Pharmaceutical Sciences, vol. 98, no. 4, pp. 1206-1219, 2009.

[12] J. V. Willis, M. J. Kendall, R. M. Flinn, D. P. Thornhill, and P. G. Welling, "The pharmacokinetics of diclofenac sodium following intravenous and oral administration," European Journal of Clinical Pharmacology, vol. 16, no. 6, pp. 405-410, 1979.

[13] MedlinePlus, U.S. National Library of Medicine, May 2015, https://www.nlm.nih.gov/medlineplus/druginfo/meds/a611001 .html.

[14] H. Vyas, J. Patel, T. P. Upadhyay, and U. M. Upadhyay, "Transdermal matrix patch as a tool for delivery of ketoprofen," International Journal of Pharmaceutical Research and Bio Science, vol. 3, no. 3, pp. 313-325, 2014.

[15] Y. Zhang, D. Cun, X. Kong, and L. Fang, "Design and evaluation of a novel transdermal patch containing diclofenac and teriflunomide for rheumatoid arthritis therapy," Asian Journal of Pharmaceutical Sciences, vol. 9, no. 5, pp. 251-259, 2014.

[16] F. Mrue, J. C. Netto, R. Ceneviva, J. J. Lachat, J. A. Thomazini, and H. Tambelini, "Evaluation of the biocompatibility of a new biomembrane," Materials Research, vol. 7, no. 2, pp. 277-283, 2014.

[17] S. L. Sader, J. Coutinho Netto, J. Barbieri Neto, S. A. Mazzetto, P. Alves Jr., and J. C. Sader, "Substituição parcial do pericárdio de cães por membrana de látex natural," Revista Brasileira de Cirurgia Cardiovascular, vol. 15, no. 4, pp. 338-344, 2000.

[18] R. D. Herculano, C. P. Silva, C. Ereno, S. A. C. Guimaraes, A. Kinoshita, and C. F. D. O. Graeff, "Natural rubber latex used as drug delivery system in guided bone regeneration (GBR)," Materials Research, vol. 12, no. 2, pp. 253-256, 2009.

[19] J. D’Auzac, H. Crétin, B. Marin, and C. Lioret, "A plant vacuolar system: the lutoids from Hevea brasiliensis latex," Physiologie Végétale, vol. 20, no. 2, pp. 311-331, 1982.

[20] J. D'Auzac, J. L. Jacob, and H. Chrestin, "The composition of latex from Hevea brasiliensis as a laticiferous cytoplasm," in Physiology of Rubber Tree Latex: The Laticiferous Cell and Latex -A Model of Cytoplasm, vol. 1, chapter 2, pp. 59-98, CRC Press, Boca Raton, Fla, USA, 2000. 
[21] K. Nawamawat, J. T. Sakdapipanich, C. C. Ho, Y. Ma, J. Song, and J. G. Vancso, "Surface nanostructure of Hevea brasiliensis natural rubber latex particles," Colloids and Surfaces A: Physicochemical and Engineering Aspects, vol. 390, no. 1-3, pp. 157-166, 2011.

[22] H. Hasma and A. Subramauian, "Composition of lipids in latex of Hevea brasiliensis clone RRIM 501," Journal of Natural Rubber Research, vol. 1, no. 1, pp. 30-40, 1986.

[23] W. Pichayakorn, J. Suksaeree, P. Boonme, T. Amnuaikit, W. Taweepreda, and G. C. Ritthidej, "Nicotine transdermal patches using polymeric natural rubber as the matrix controlling system: effect of polymer and plasticizer blends," Journal of Membrane Science, vol. 411-412, pp. 81-90, 2012.

[24] J. Suksaeree, P. Boonme, W. Taweepreda, G. C. Ritthidej, and W. Pichayakorn, "Characterization, in vitro release and permeation studies of nicotine transdermal patches prepared from deproteinized natural rubber latex blends," Chemical Engineering Research and Design, vol. 90, no. 7, pp. 906-914, 2012.

[25] H. D. Murbach, G. I. Ogawa, F. A. Borges et al., "Ciprofloxacin release using natural rubber latex membranes as carrier," International Journal of Biomaterials, vol. 2014, Article ID 157952, 7 pages, 2014.

[26] P. B. Aielo, F. A. Borges, K. M. Romeira et al., "Evaluation of sodium diclofenac release using natural rubber latex as carrier," Materials Research, vol. 17, supplement 1, pp. 146-152, 2014.

[27] K. M. Romeira, B. C. Drago, H. D. Murbach et al., "Evaluation of Stryphnodendron sp. Release using natural rubber latex membrane as carrier," Journal of Applied Sciences, vol. 12, no. 7, pp. 693-697, 2012.

[28] K. K. Kim and D. W. Pack, BioMEMS and Biomedical Nanotechnology XX, Springer, 2016.

[29] R. D. Herculano, S. A. C. Guimarães, G. C. Belmonte et al., "Metronidazole release using natural rubber latex as matrix," Materials Research, vol. 13, no. 1, pp. 57-61, 2010.

[30] R. D. Herculano, L. C. Tzu, C. P. Silva et al., "Nitric oxide release using natural rubber latex as matrix," Materials Research, vol. 14, no. 3, pp. 355-359, 2011.

[31] A. Semalty, M. Semalty, D. Singh, and M. S. M. Rawat, "Development and physicochemical evaluation of pharmacosomes of diclofenac," Acta Pharmaceutica, vol. 59, no. 3, pp. 335-344, 2009.

[32] R. B. Shinde, J. S. Raut, N. M. Chauhan, and S. M. Karuppayil, "Chloroquine sensitizes biofilms of Candida albicans to antifungal azoles," Brazilian Journal of Infectious Diseases, vol. 17, no. 4, pp. 395-400, 2013.

[33] R. Langer and J. Folkman, "Polymers for the sustained release of proteins and other macromolecules," Nature, vol. 263, no. 5580, pp. 797-800, 1976.

[34] M. Löbler, K. Sternberg, O. Stachs et al., "Polymers and drugs suitable for the development of a drug delivery drainage system in glaucoma surgery," Journal of Biomedical Materials Research Part B: Applied Biomaterials, vol. 97, no. 2, pp. 388-395, 2011.

[35] P. J. Goddard, Y.-C. J. Kao, and L. M. Lichtenberger, "Luminal surface hydrophobicity of canine gastric mucosa is dependent on a surface mucous gel," Gastroenterology, vol. 98, no. 2, pp. 361-370, 1990.

[36] H. Maswadeh, A. Abdulhalim, and C. Demetzos, "Improvement of encapsulation efficiency of diclofenac sodium in to uncoated and chitosan-coated liposomes," Indian Journal of Pharmaceutical Sciences, vol. 66, no. 5, pp. 607-612, 2004.
[37] L. Y. Wang, Y. H. Gu, Q. Z. Zhou, G. H. Ma, Y. H. Wan, and Z. G. Su, "Preparation and characterization of uniformsized chitosan microspheres containing insulin by membrane emulsification and a two-step solidification process," Colloids and Surfaces B: Biointerfaces, vol. 50, no. 2, pp. 126-135, 2006.

[38] I. Tariq, A. M. Mumtaz, T. Saeed et al., "In vitro release studies of diclofenac potassium tablet from pure and blended mixture of hydrophilic and hydrophobic polymers," Latin American Journal of Pharmacy, vol. 31, no. 3, pp. 380-387, 2012.

[39] S. D. Ray, K. Ghosal, I. Ghosal, and D. Ghosh, "Alginate/hydrophobic HPMC (60L) particulate systems: new matrix for controlled release of diclofenac potassium," Latin American Journal of Pharmacy, vol. 30, no. 5, pp. 945-951, 2011. 

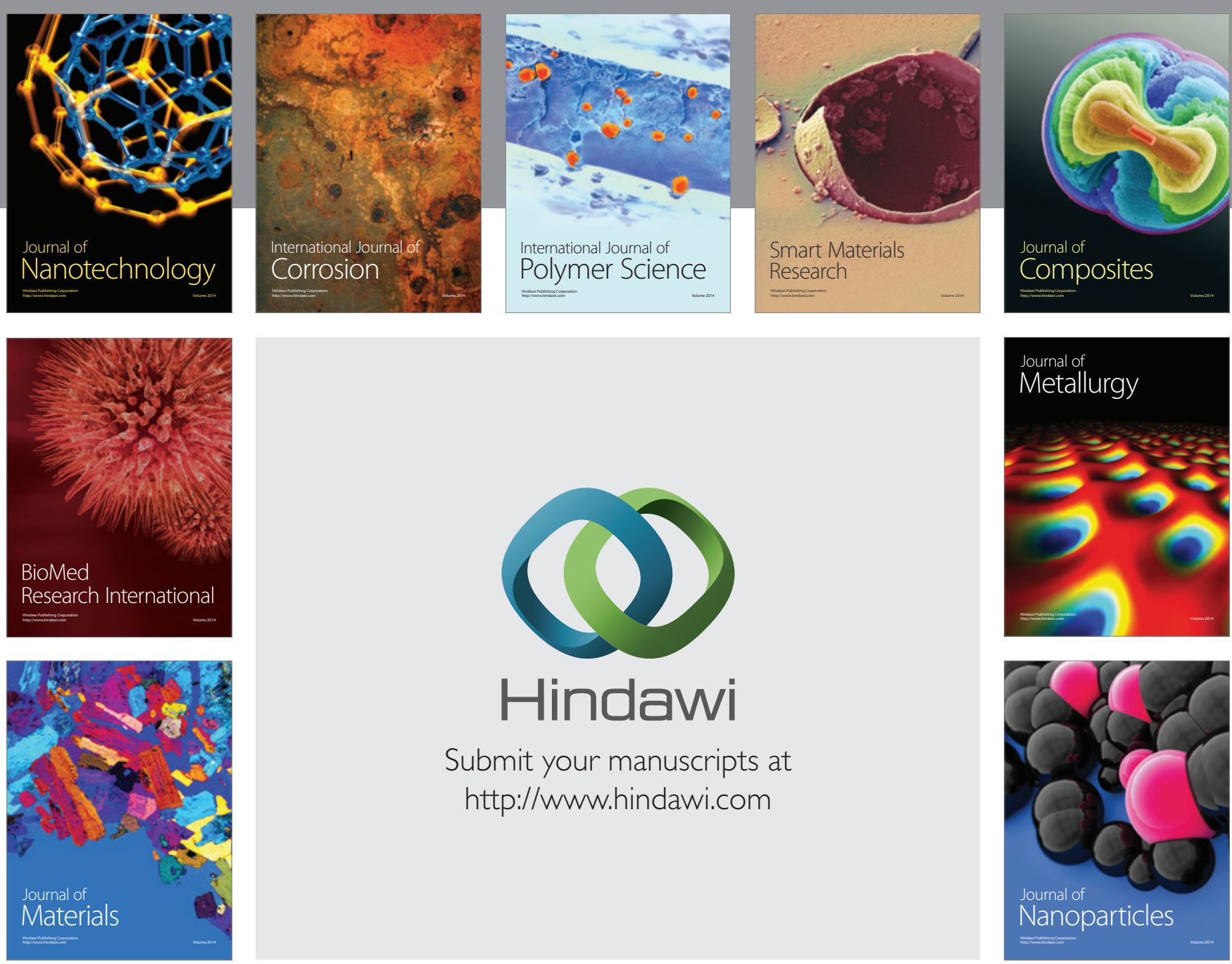

Submit your manuscripts at http://www.hindawi.com
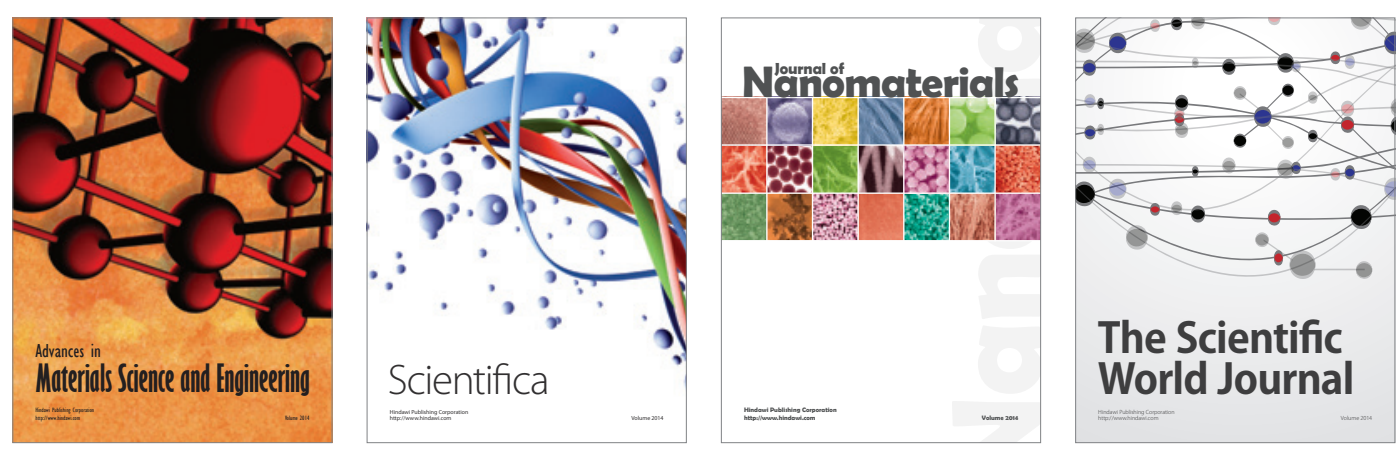

\section{The Scientific World Journal}
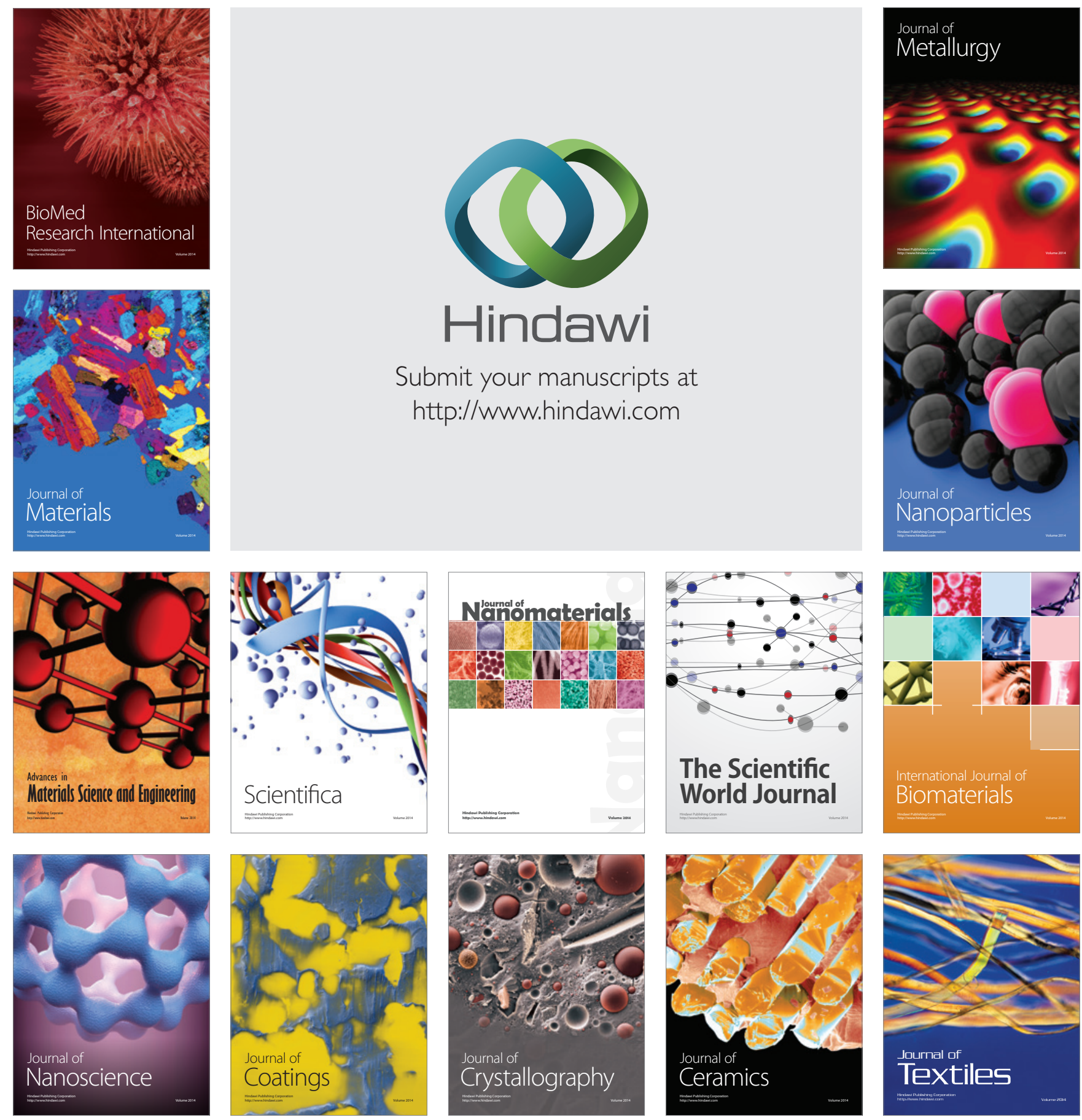